\title{
Correspondence
}

\section{Don't let the Bain take the blame}

To the Editor:

We were interested to read the report of an occluded breathing system resulting in failure of inhalational induction of anaesthesia. ${ }^{1}$ The accompanying photograph clearly illustrated the cause of obstruction, a cylindrical metal object, located in the angle-piece connecting the face mask to a breathing system which in this case happened to be a Bain circuit. As the authors correctly point out, the same clinical situation could have occurred with any breathing system. Perhaps it would have been more appropriate to title this case report "Angle-piece occluded by a foreign body"?

The authors qualified the sole use of pulse oximetry during induction of anaesthesia with the intention of establishing ECG, temperature, non-invasive blood pressure monitoring and vascular access immediately after induction was achieved, but, curiously, did not state if or when capnography was to be used. Prior incorporation of a capnograph sampling tube between the Bain circuit and the angle-piece may have afforded closer scrutiny of the angle-piece during the disconnection and reconnection procedure. Also, assuming an adequate face-mask seal, the absence of a typical capnograph trace is a useful indicator of lack of airway continuity or patency ${ }^{2}$ and may have been of particular benefit in this case. Nevertheless, we believe that such an error should be identified before use of the breathing system on a patient.

We disagree with the authors' conclusions. In attempting to define a method that includes the Bain circuit and the angle-piece they advocate adaptation of anecdotal tests which are insensitive and unreliable indicators of integrity of the inner tubing of the Bain circuit. Rather than perform such tests with the angle-piece present, it would be preferable to perform a more sensitive and reliable check which requires removing the angle-piece. ${ }^{3}$ Thorough inspection of the remaining components, as the authors comment, would then have detected the foreign body. We consider this to be the essential message of the case report.

D.R. Uncles MB FFARCSI, FRCA

T.J. Parke MB FRCA MRCP MRCSP

Department of Anesthesiology
University of Virginia

Charlottesville, VA 22908

\section{REFERENCES}

1 Wilkes $P R H$, Lindsay PA. Bain circuit occluded by foreign body. Can J Anaesth 1994; 41: 137-9.

2 Block FE. A proposed standard for monitoring equipment: what equipment should be included? J Clin Monit 1988; 4: $1-4$.

3 Heath PJ, Marks LF. Modified occlusion tests for the Bain breathing system. Anaesthesia 1991; 46: 213-6.

\section{Tracheal obstruction}

To the Editor:

We read the article "Jet ventilation in a case of tracheal obstruction secondary to retrosternal goitre" by Baraka et al. ${ }^{1}$ and would like to congratulate the authors on their management. However, we question inhalational induction (following awake tracheal intubation) in this patient with severe airway obstruction as inhalational induction may be delayed in these cases. Also, as the patient was already hypercapnic halothane may induce dysarrythmias. ${ }^{2}$ Isoflurane might have been a better choice. We feel $i v$ induction with thiopentone would have been preferable.

The authors suggested that spontaneous ventilation is safer than controlled ventilation even after successful awake tracheal intubation. We disagree because after ensuring adequate ventilation, it is advisable to switch to controlled ventilation. Spontaneous respiration, if continued in a patient with obstructed airway, might lead to pulmonary oedema. ${ }^{3}$

Anil Agarwal MD

Soma Kaushik DA MS MNAMS

Department of Anaesthesiology \& Critical Care Medicine SGPGIMS, Lucknow, India

\section{REFERENCES}

1 Baraka A, Muallem $M$, Jamhoury $M$, Choueiry $P$. Jet ventilation in a case of tracheal obstruction secondary to a retrosternal goitre. Can J Anaesth 1993; 40: 875-8.

2 Coleman AJ. Inhalational anaesthetic agents. In: Churchill Davidson HC (Ed.). A Practice of Anaesthesia, 4th ed., London: Lloyd-Luke Ltd, 1978: 238-303. 